\title{
Thematic issue: water environment of the Three Gorges Reservoir
}

\author{
Binghui Zheng ${ }^{1} \cdot$ Yanwen Qin ${ }^{1} \cdot$ Defu Liu $^{2} \cdot$ Stefan Norra ${ }^{3} \cdot$ Shengrui Wang ${ }^{1}$
}

Received: 22 May 2017 / Accepted: 27 October 2017 / Published online: 16 December 2017

c) Springer-Verlag GmbH Germany, part of Springer Nature 2017

The Three Gorges Project is a key project for China to develop and control the Yangtze River, and it is currently one of the largest hydro-engineering projects in the world. The Three Gorges Dam (TGD) is located in the Yichang City of Hubei Province and controls a catchment area of 1 million $\mathrm{km}^{2}$ which accounts for $56 \%$ of the Yangtze River basin area. After the completion of the TGD, the interception and impoundment formed an "artificial lake" in the Yangtze River Valley, known as the Three Gorges Reservoir (TGR). The TGR lies in midlatitude region $\left(28^{\circ} 32^{\prime} \mathrm{N}-31^{\circ} 44^{\prime} \mathrm{N}\right.$, $105^{\circ} 44^{\prime} \mathrm{N}-111^{\circ} 39^{\prime} \mathrm{N}$ ) with a river length of $667 \mathrm{~km}$ and a total water surface area of $1084 \mathrm{~km}^{2}$ (Fig. 1). Under the normal storage water level of $175 \mathrm{~m}$ a.s.l. and the flood control water level of $145 \mathrm{~m}$ a.s.l., the TGR has a total storage capacity of 39.3 billion $\mathrm{m}^{3}$ and a flood control capacity of 22.15 billion $\mathrm{m}^{3}$. The TGR is situated in a subtropical humid monsoon climate with an annual mean temperature of $16.6^{\circ} \mathrm{C}$ and an annual mean rainfall of $1124.5 \mathrm{~mm}$. The rainfall in the TGR area is most intensive from April to October, counting for roughly $80 \%$ of annual total rainfall.

The TGR experienced three-step experimental impoundment in June 2003, October 2006 and November 2008, during which the storage water level reached 145, 156 and $175 \mathrm{~m}$, respectively. After that, the TGR is managed according to an annual operation mode as: (i) each year

This article is part of a Topical Collection in Environmental Earth Sciences on "Environmental Research of the Three Gorges Reservoir", guest edited by Binghui Zheng, Shengrui Wang, Yanwen Qin, Stefan Norra, and Xiafu Liu.

Binghui Zheng

zhengbinghui@craes.org.cn

1 Chinese Research Academy of Environmental Sciences, Dayangfang 8, Anwai Beiyuan, Chaoyang District, Beijing 100012, China

2 College of Resources and Environment Sciences, Hubei University of Technology, Wuhan 430068, Hubei, China

3 Institute of Applied Geosciences (AGW), Karlsruhe Institute of Technology (KIT), Adenauerring 20b, 76131 Karlsruhe, Germany from February to June, the reservoir water level gradually is reduced from $175 \mathrm{~m}$ to the flood control level of $145 \mathrm{~m}$; (ii) from July to August, the reservoir water runs at a low level of $145 \mathrm{~m}$; (iii) from September to October, the reservoir water level is gradually impounded from 145 to $175 \mathrm{~m}$; (iv) from November to January of the following year, the reservoir water is maintained at a high level of $175 \mathrm{~m}$ (Fig. 2). The TGR impoundment has brought tremendous economic and social benefits by flood control, power generation, shipping, tourism, water supply, irrigation and so on (Cao 2012; Qiu et al. 2003). At present, the Three Gorges Power Plant annually generates about 100 billion $\mathrm{kWh}$, saving 20-25 billion RMB per year calculated by standard coal price (Wang 2007; Zhou 2006).

However, as a consequence of dam construction and operation, the natural flow regime of the Yangtze River is disturbed and a number of negative environmental impacts and uncertainties on the upstream and downstream areas cannot be avoided (Müller et al. 2008; Qiu 2012; Tan et al. 2010). The TGR is an important freshwater resource reservoir in China, which is also an ecological sensitive area with significance (Du et al. 2009). Since the establishment of TGD in 1990s, the Chinese government and related departments have set up a number of scientific research projects studying the environmental characteristics and environmental impacts of TGR, including the national key scientific projects and technological projects. From the ninth 5-year plan time period to the thirteen 5-year plan time period, the project covered the sustainable development and ecological rehabilitation model of the environmental changes in the upstream area of the Yangtze River, the ecological security protection and ecological economy system reconstruction in the TGR, the application of the ecological restoration and comprehensive treatment technology in the water-level fluctuation zone of the TGR and the application of water pollution prevention and algae bloom control technology in the TGR, etc. In addition, some international cooperation projects have also been launched, for example the Sino-German cooperation project YANGTZE, which focused on the research of water environment characteristics and tributaries eutrophication 
Fig. 1 Location of the Three Gorges Reservoir in China

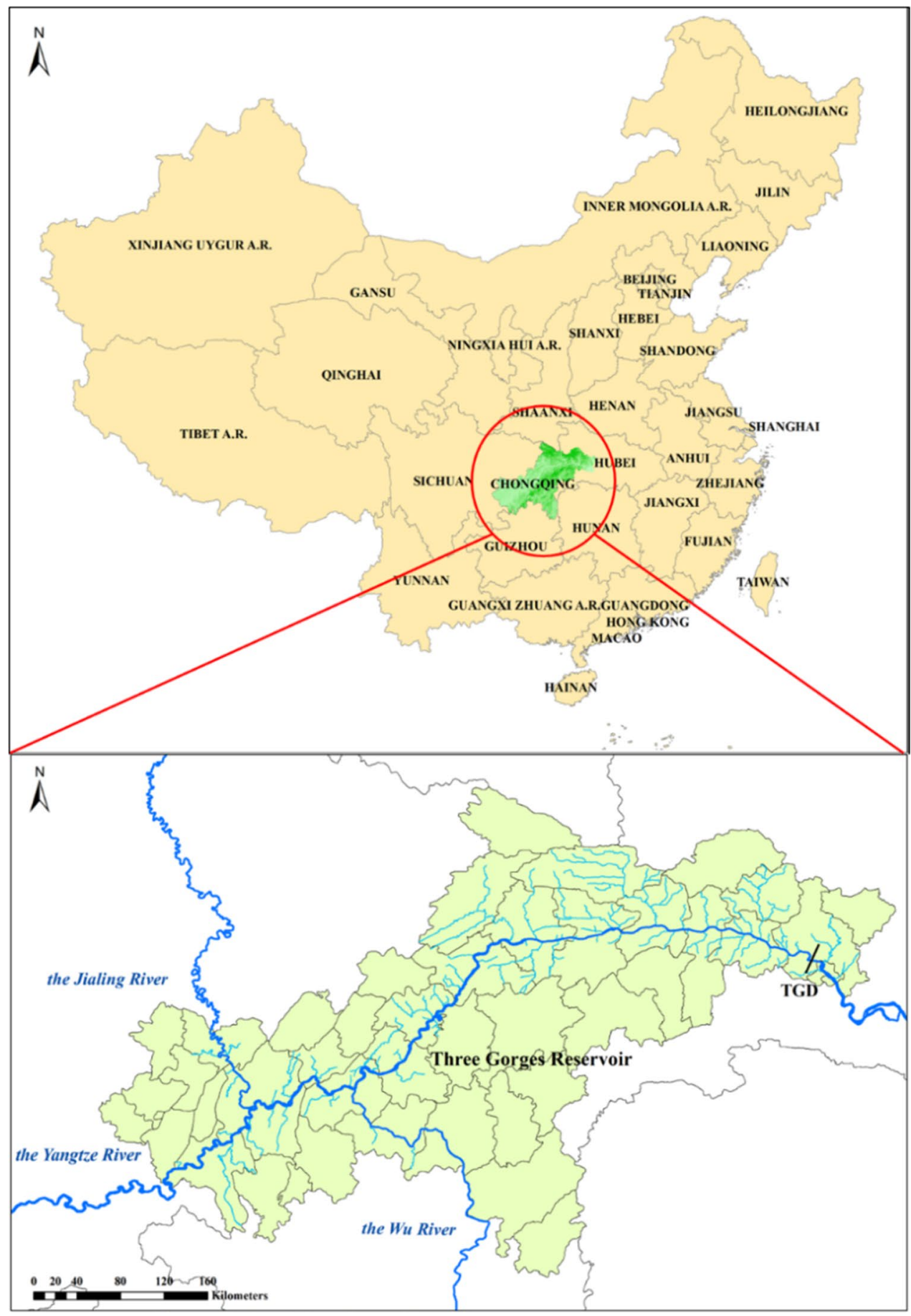

mechanism in the TGR. Based on these scientific research projects, some common negative environmental impacts brought by the TGR impoundment have been well discussed:

Water eutrophication and algae bloom occurrence in the TGR tributaries After the impounding of the TGR, the TGR mainstream is still considered mesotrophic, whereas the TGR tributaries changed from mesotrophic to eutrophic or hypereutrophic (Cai and Hu 2006; Cai and Sun 2012). Furthermore, algae blooms in the TGR tributaries have been reported to occur in spring, summer and autumn each year since 2003 (CNEMC 2013). It is generally known that water eutrophication caused by excessive nutrient inputs is one of the main factors contributing to algae bloom formation (Schindler and Fee 1974). However, studies indicated that the changes in hydrodynamics and meteorological conditions due to the TGR impoundment were the driven factors of algae bloom formation (Yang 2014). Sensitive areas especially are where tributaries meet the main stream of 


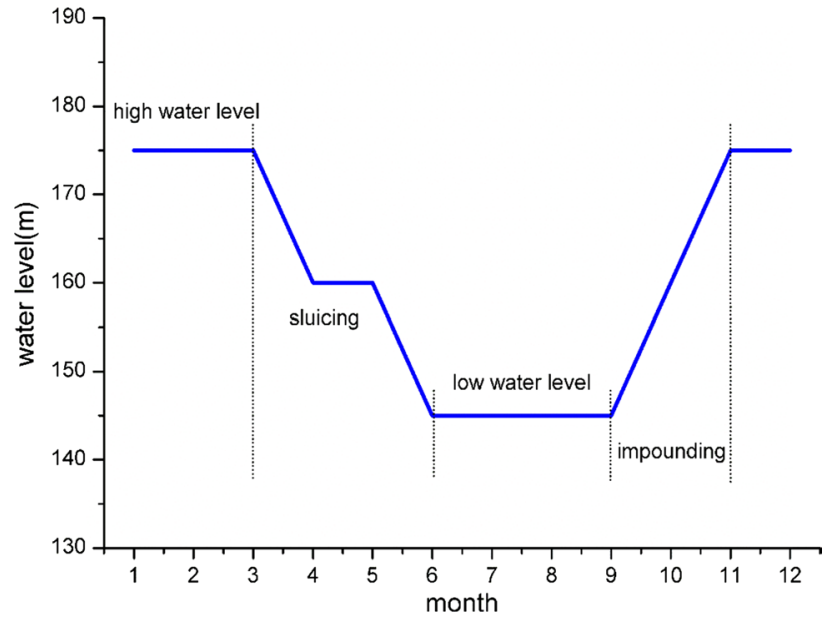

Fig. 2 Water level changes in the TGR under the scheduling operation annually (Han et al. 2016)

Yangtze due to specific flow patterns caused by the extreme high flow rate of the Yangtze river $\left(>10.000 \mathrm{~m}^{3}\right)$ and the relatively low ones of the tributaries $\left(<1000 \mathrm{~m}^{3}\right)$ (Holbach et al. 2013, 2014). Previous studies showed that the TGR impoundment deepened water level, slowed water velocity, prolonged water retention time and reduced water self-purification capacity in the TGR, particularly in the backwater area of the TGR tributaries (Xiao et al. 2009). The changed hydrodynamics were easy to form thermal stratification in the TGR tributaries, which lead to the occurrences of algae blooms under appropriate meteorological conditions (Holbach et al. 2013, 2014; Liu et al. 2012; Yang 2014).

Land use change and soil erosion in the TGR basin The TGR basin is one of the most serious soil erosion areas in China, and the average of soil erosion amount and soil erosion modulus reached 19,364.71 $\times 10^{4} \mathrm{t} / \mathrm{a}$ and $2741.48 \mathrm{t} /\left(\mathrm{km}^{2} \mathrm{a}\right)$, respectively (Long et al. 2012). It was reported that the TGD construction caused land utilization changes in the TGR area, characterized by size, scenic features, land use pattern and land use degree, etc. (Cao et al. 2007). From 1977 to 2005, statistic data indicated that about $2 \mathrm{~km}^{2}$ arable land in the TGR basin was applied for other purposes annually, and arable lands with slope grade less than $25^{\circ}$ in the TGR basin decreased dramatically, but those with slope grade more than $25^{\circ}$ almost remained the same (Zhang et al. 2009). Due to reservoir water management, the water-level fluctuation zone with an area of $349 \mathrm{~km}^{2}$ was formed in the river bank of the TGR mainstream (Zhang 2013). The periodic alternation of wetting and drying in the water-level fluctuation zone affected the migration and transformation of nutrients in soils (Yuan et al. 2007). Previous study indicated that water eutrophication in the reservoir mostly occurred around the waterlevel fluctuation zone during the impounding period of the
TGR, which was related to slow water velocity, sufficient sunlight, as well as the release of nitrogen and phosphorus from the soil to the water (Shi 2014). Thus, the nutrient inputs from water-level fluctuation zone by soil erosion were possible nutrient sources of the TGR and can influence nutrient distribution in water of the TGR.

Ecological security in the TGR The TGR impoundment has caused fundamental changes on the habitat environment of the aquatic organism in the TGR and thus influenced the species communities and the biomass of aquatic organisms in the TGR. Dai et al. found an acute increase in algae species in the TGR tributaries after the impounding of the TGR, as well as a significant increase in nutrient concentrations (Dai et al. 2010). Shen et al. indicated that the biodiversity of aquatic organisms in the TGR became more fragile after the TGR impoundment than before (Shen 2010). During the past three decades, previous studies indicated that the eco-environmental quality in the Daning River, a tributary of the TGR, was gradually falling into the middle or poor levels (Ma et al. 2008).

Geological disaster in the TGR The TGR area is among the typical areas where geological disasters would easily happen. Since the initial operation of the TGR in 2003, the occurrences of geological disasters including collapses and landslides have significantly increased due to the periodic fluctuation of water level in the TGR. Liu et al. recorded that there were 5706 geological disaster points in the TGR region, including 3830 landslide points, 1107 unstable slopes, 549 collapse points, 90 mudslide points, 85 ground subsidence points and 45 ground fissure points (Liu et al. 2004).

From the perspective of ecology, it has only been over one decade since the initial impoundment of the TGR; thus, the reservoir ecosystem is still in constant adjustment and gradual stabilization. To recognize the latest situation of ecological environment in the TGR, to explore the eco-environmental effects and to promote the ecological environment of the TGR, "Environmental Earth Science" edited this thematic issue on "Environmental Research of the Three Gorges Reservoir," which contains 16 articles mainly focusing on nutrient imports of the upstream rivers of the TGR (Han et al. 2016; Ren et al. 2016; Zheng et al. 2016), eutrophication problem in the tributary bay (Cui et al. 2016; Zhang et al. 2016a) and water quality changes in the reservoir area (Huang et al. 2016; Kranzioch-Seipel et al. 2016; Zhao et al. 2016). There are also articles studying the land use change (Teng et al. 2016; Wang et al. 2016) and geological disasters in the TGR region (Chen et al. 2016; Dumperth et al. 2016; Guo et al. 2016; Zhang et al. 2016b). Furthermore, the optimal TGR operation mode is analyzed from the perspective of ecological water level of the downstream of the TGR (Dai et al. 2016). 


\section{References}

Cai QH, Hu ZY (2006) Studies on eutrophication problem and control strategy in the Three Gorges Reservoir. Acta Hydrobiol Sin 30:7-11 (in Chinese)

Cai QH, Sun ZY (2012) Water environment and aquatic ecosystem of Three Gorges Reservoir, China: progress and prospects. J Lake Sci 24:169-177 (in Chinese)

Cao GJ (2012) Fully expand the comprehensive benefits of the Three Gorges Project China. Water Resour 14:7-8 (in Chinese)

Cao YG, Wang J, Liu ZJ, Cheng Y, Liu AX, Xu N (2007) Analyses on temporal-spatial traits of land use in three gorges during 30 years. Sci Surv Mapp 32:167-170 (in Chinese)

Chen T, Niu R, Jia X (2016) A comparison of information value and logistic regression models in landslide susceptibility mapping by using GIS. Environ Earth Sci 75:1-16. https://doi.org/10.1007/ s12665-016-5317-y

CNEMC (2013) Bulletin of ecological and environmental monitoring of the Three Gorges Project in the Yangtze River. Ministry of Environmental Protection of the People's Republic of China (in Chinese)

Cui YJ et al (2016) Diel migration of microcystis during an algal bloom event in the Three Gorges Reservoir, China. Environ Earth Sci 75:1-9. https://doi.org/10.1007/s12665-015-5124-x

Dai HC, Zheng TG, Liu DF (2010) Effects of reservoir impounding on key ecological factors in the three gorges region. Procedia Environ Sci 2:15-24. https://doi.org/10.1016/j.proenv.2010.10.004

Dai L, Mao J, Wang Y, Dai H, Zhang P, Guo J (2016) Optimal operation of the Three Gorges Reservoir subject to the ecological water level of Dongting Lake. Environ Earth Sci 75:1-14. https://doi. org/10.1007/s12665-016-5911-z

Du FB, Chen JP, Shi JH (2009) Three Gorges Reservoir Area of the environment charged with evaluation and management of the ecological environment. Urban Geotech Invest Surv 2:150-152 (in Chinese)

Dumperth C, Rohn J, Fleer A, Xiang W (2016) Local-scale assessment of the displacement pattern of a densely populated landslide, utilizing finite element software and terrestrial radar interferometry: a case study on Huangtupo landslide (P.R. China). Environ Earth Sci 75:1-9. https://doi.org/10.1007/s12665-016-5475-y

Guo F, Luo Z, Li H, Wang S (2016) Self-organized criticality of significant fording landslides in Three Gorges Reservoir area, China. Environ Earth Sciences 75:1-15. https://doi.org/10.1007/ s12665-016-5465-0

Han C, Zheng B, Qin Y, Ma Y, Cao W, Yang C, Liu Z (2016) Analysis of phosphorus import characteristics of the upstream input rivers of Three Gorges Reservoir. Environ Earth Sci 75:1-10. https:// doi.org/10.1007/s12665-016-5832-x

Holbach A, Wang LJ, Chen H, Hu W, Schleicher N, Zheng BH, Norra S (2013) Water mass interaction in the confluence zone of the Daning River and the Yangtze River-a driving force for algal growth in the Three Gorges Reservoir. Environ Sci Pollut Res 20:7027-7037. https://doi.org/10.1007/s11356-012-1373-3

Holbach A, Norra S, Wang LJ, Yuan YJ, Wei H, Zheng BH, Bi YH (2014) Three Gorges Reservoir: density Pump Amplification of Pollutant Transport into Tributaries. Environ Sci Technol 48:7798-7806. https://doi.org/10.1021/es501132k

Huang Y, Fan D, Liu D, Song L, Ji D, Hui E (2016) Nutrient estimation by HJ-1 satellite imagery of Xiangxi Bay, Three Gorges Reservoir, China. Environ Earth Sci 75:1-13. https://doi.org/10.1007/ s12665-016-5421-z

Kranzioch-Seipel I, Beckert U, Shen C, Yin D, Tiehm A (2016) Microbial dechlorination of HCB, PCP, PCB180 HCH and PCE in a Yangtze Three Gorges Reservoir enrichment culture, China. Environ Earth Sci 75:1-9. https://doi.org/10.1007/s12665-016-5653-y
Liu CZ, Li TF, Wen MS, Wang XP, Yang B (2004) Assessment and early warning on geo-hazards in the Three Gorges Reservoir region of Changjiang River. Hydrogeol Eng Geol 4:9-18 (in Chinese)

Liu L, Liu DF, Johnson DM, Yi ZQ, Huang YL (2012) Effects of vertical mixing on phytoplankton blooms in Xiangxi Bay of Three Gorges Reservoir: implications for management. Water Res 46:2121-2130. https://doi.org/10.1016/j.watres.2012.01.029

Long TY, Qiao D, An Q, Du K (2012) Estimating soil erosion in Three Gorges Reservoir Area based on GIS and RUSLE. J Irrig Drain 31:33-37 (in Chinese)

Ma ZZ, Zhuo JS, Zhang HZ (2008) Study on ecological environmental quality dynamical assessment of Daninghe River watershed in the Three Gorges Reservoir area. Environ Ecol Three Gorges 1:6-10 (in Chinese)

Müller B, Berg M, Yao ZP, Zhang XF, Wang D, Pfluger A (2008) How polluted is the Yangtze river? Water quality downstream from the Three Gorges Dam. Sci Total Environ 402:232-247. https://doi. org/10.1016/j.scitotenv.2008.04.049

Qiu J (2012) Trouble on the Yangtze. Science 336:288-291. https:// doi.org/10.1126/science.336.6079.288

Qiu ZE, Tan CL, Zhang H, Xiang F (2003) On comprehensive benefit of the Three Gorges Project of the Yangtze river. Yangtze River 34:43-46 (in Chinese)

Ren C, Wang L, Zheng B, Qian J, Ton H (2016) Ten-year change of total phosphorous pollution in the Min River, an upstream tributary of the Three Gorges Reservoir. Environ Earth Sci 75:1-11. https://doi.org/10.1007/s12665-016-5789-9

Schindler D, Fee E (1974) Experimental lakes area: whole lakes experiment in eutrophication. J Fish Res Board Can 31:937-953

Shen GF (2010) The Three Gorges Project's impacts on ecology and environment. Sci Chin S1:48-53 (in Chinese)

Shi XH (2014) Eutropication and phosphorus release of soil in drawdown area of Three Gorges Reservoir. Soil Fertil 1:40-44 (in Chinese)

Tan L, Cai QH, Xu YY, Shen HL (2010) Survey of spring eutrophication status after $175 \mathrm{~m}$ experimental impoundment of Three Gorges Reservoir and comparison wet land. Science 8:331-338 (in Chinese)

Teng M, Zeng L, Zhou Z, Wang P, Xiao W, Dian Y (2016) Responses of landscape metrics to altering grain size in the Three Gorges Reservoir landscape in China. Environ Earth Sci 75:1-13. https:// doi.org/10.1007/s12665-016-5605-6

Wang XG (2007) 700 questions for the Three Gorges Resettlement Project Beijing. China Three Gorges Publishing House, Yichang (in Chinese)

Wang L-J, Wu L, Hou X-Y, Zheng B-H, Li H, Norra S (2016) Role of reservoir construction in regional land use change in Pengxi River basin upstream of the Three Gorges Reservoir in China. Environ Earth Sci 75:1-15. https://doi.org/10.1007/s12665-016-5758-3

Xiao TY, Xu XY, Fu YC, Luo GY (2009) Discussion on the eutrophication and ecological engineering technologies for secondary rivers in the Three-Gorge Reservoir. J Chongqing Univ 15:5-8 (in Chinese)

Yang ZJ (2014) The Mechanisms of algal blooms and its operation method through water level fluctuation under the situation of the bidirectional density currents in tributaries of the Three Gorges Reservoir. Wuhan University, Wuhan, pp 80-103 (in Chinese)

Yuan H, Huang C, Cui ZQ, Hu G, Bao L (2007) Forecast of the relation between the water quality and the wet-dry zone of the Three Gorges Area. J Chongqing Univ (Natural Science Edition) 30:134-138 (in Chinese)

Zhang B (2013) Study on distribution characteristics and flux of organic matter, nitrogen and phosphorus in the soil of WLFZ of Three Gorges Reservoir. Chongqing University, Chongqing, p 105 (in Chinese) 
Zhang J, Zhengjun L, Xiaoxia S (2009) Changing landscape in the Three Gorges Reservoir Area of Yangtze River from 1977 to 2005: land use/land cover, vegetation cover changes estimated using multi-source satellite data. Int J Appl Earth Obs Geoinf 11:403-412. https://doi.org/10.1016/j.jag.2009.07.004

Zhang JL, Wang LJ, Zheng BH, Liu DF, Yang ZJ (2016a) Eutrophication status of the Daning River within the Three Gorges Reservoir and its controlling factors before and after experimental impoundment. Environ Earth Sci 75:1-11. https://doi.org/10.1007/ s12665-016-5931-8

Zhang M, Cao X, Peng L, Niu R (2016b) Landslide susceptibility mapping based on global and local logistic regression models in Three Gorges Reservoir area, China. Environ Earth Sci 75:1-11. https:// doi.org/10.1007/s12665-016-5764-5
Zhao Y, Qin Y, Zhang L, Zheng B, Ma Y (2016) Water quality analysis for the Three Gorges Reservoir, China, from 2010 to 2013. Environ Earth Sci 75:1-12. https://doi.org/10.1007/ s12665-016-5954-1

Zheng B, Zhao Y, Qin Y, Ma Y, Han C (2016) Input characteristics and sources identification of nitrogen in the three main tributaries of the Three Gorges Reservoir, China. Environ Earth Sci 75:1-10. https://doi.org/10.1007/s12665-016-6028-0

Zhou XR (2006) How to understand the historic and contemporary significance of the Three Gorges Project. Fronters 1:31-49 (in Chinese) 